\title{
Acellular pertussis vaccine for adolescents
}

\author{
Aroldo P. de Carvalho, ${ }^{1}$ Eliane Mara Cesário Pereira²
}

\begin{abstract}
Background: The use of whole-cell pertussis vaccine has led to a significant decline in incidence of the disease among children. This change in the epidemiological profile led to an increased number of cases among teenagers and adults, as a result of loss of immunity to the disease or vaccine after approximately 10 years. An increased number of cases was also observed among non-immunized or partially immunized infants. Licensure of the DTP vaccine against diphtheria, tetanus, and acellular pertussis formulated specifically for patients over 10 years of age (Tdap) suggests the possibility of controlling pertussis in the most affected age groups over the past few years.

Sources of data: Data were collected from MEDLINE. The research was limited to the period between January 1995 and January 2006.

Summary of the findings: In some countries there are two Tdap vaccines licensed for patients over 10 years of age. One of them contains five immunogenic components of Bordetella pertussis (pertussis toxin, filamentous hemagglutinin, fimbriae 2 and 3, and pertactin), and the other contains three components (pertactin, filamentous hemagglutinin, and inactivated pertussis toxin), the latter being the only one licensed in Brazil up to now. Although the composition of the two vaccines differs, studies show that they have similar effectiveness and immunogenicity. Some authors, however, emphasize that it is difficult to make a precise assessment of the immunological response to the vaccine and its duration. Several countries currently recommend the use of Tdap vaccine for adolescents. Canada has extended the target population up to 54 years of age. The guideline is that this group should receive one dose of the vaccine to reinforce the basic immunization scheme. This is based on study results that show that the vaccine-induced immunity lasts for around 6 to 12 years. Assessments of the economic impact of routine use of the vaccine in adolescents showed a positive cost-benefit ratio. Results of the epidemiological impact depend on the quality of diagnosis so that data reflect the reality of the disease.

Conclusions: Although some questions remain to be clarified, the literature indicates the possibility of solving the "reappearance" of whooping cough (pertussis) with the use of Tdap vaccine. Perhaps the strategy of using a second booster dose in adolescence to replace the double diphtheria and tetanus vaccine should be adopted immediately.
\end{abstract}

J Pediatr (Rio J). 2006;82(3 Suppl):S15-24: Pertussis, whooping cough, pertussis vaccine, vaccine for adolescents, acellular vaccine.

\section{Introduction}

The routine use of the whole-cell pertussis vaccine has led to a significant reduction in the incidence of the disease in various countries around the world, with a reduction in morbidity and mortality. However, infants up to six months who did not receive the basic vaccination scheme remain susceptible and, when infected by Bordetella pertussis, may present atypical symptoms when compared with older children. ${ }^{1}$

1. Doutor em Pediatria. Professor adjunto, Universidade Federal de Santa Catarina (UFSC), Florianópolis, SC, Brasil, e Universidade do Vale do Itajaí (UNIVALI), Itajaí, SC, Brasil. Infectologista pediatra, Hospital Infantil Joana de Gusmão (HIJG), Florianópolis, SC, Brasil.

2. Doutora em Medicina Interna. Professora adjunta, Departamento de Clínica Médica, Universidade Federal do Paraná (UFPR), e Curso de Medicina, Centro Universitário Positivo (UNICENP), Curitiba, PR, Brasil.

Suggested citation: de Carvalho AP, Pereira EM. Acellular pertussis vaccine for adolescents. J Pediatr (Rio J). 2006;82(3 Suppl):S15-24.
Over the past few years there have been several reports concerning the severity of pertussis in infants, such as the nine cases reported in the United Kingdom by Smith \& Vyas, ${ }^{1}$ of which six led to death. Severe complications were observed, such as apnea, seizures, respiratory insufficiency, arterial hypotension, pulmonary hypertension, pneumothorax, and secondary bacterial infections.

More recently, another study conducted in the United Kingdom showed that among the 142 infants under five months of age who were hospitalized with a clinical condition of severe respiratory insufficiency, $23 \%$ had pertussis. The study also drew attention to the severity of the infection in this age group, and to the high frequency of undiagnosed cases. ${ }^{2}$

The number of deaths caused by pertussis has increased in the USA. During the 1980s, 77 deaths were 
notified, 61 being infants ( 1.7 deaths/million) and 49 infants under four months of age. In the 1990s, 103 deaths were notified, 93 being infants ( 2.4 deaths/ million), including 84 infants under four months of age. ${ }^{3}$

In Canada, all of the 16 deaths by whooping cough notified between 1991 and 2001 occurred in children under the age of 6 months, and 13 were under two months old. The presence of leucocytosis and pneumonia were predictive of poor prognosis. 4

Scientific evidence has shown that neither the immunity acquired by Bordetella pertussis infection, nor the immunity induced by vaccines is lasting. In Australia, implementing a fifth dose of pertussis vaccine reduced the incidence of the disease in children between five and ten years of age, and increased it among those between 12 and 14 years of age. ${ }^{5}$ This shift in age group is a clear indication that there is no lasting immunity acquisition.

The loss of immunity after about 10 years of receiving the last dose of vaccine makes the adolescent susceptible to infection, which has been shown in recent epidemiologic data. Of the 11,546 pertussis cases notified to the USA health authorities up to week 42 of 2004, $40 \%$ were related to the age group between 10 and 19 years of age. Adolescents and adults are frequently a source of infection to infants, as has been observed in several studies. ${ }^{6}$

A study recently conducted in Brazil found cases of pertussis in 57 cohabiting family members of children with diagnosis established by the World Health Organization (WHO) criteria. The disease was confirmed in 158 of the 349 family members, of whom 65 were primary and 93 secondary cases. Among the 37 children under the age of six months, 28 (75\%) were secondary cases. The primary cases occurred in children older than 11 years, and in $79 \%$ of all the secondary cases the children were older than six months; it occurred in $76 \%$ of cases when the secondary case was under six months of age. ${ }^{7}$

For some years the scientific community and health professionals were under the impression that pertussis was controlled in countries with adequate vaccine coverage. Many of these professionals were skeptical about believing that children with clinical manifestations suggestive of pertussis and hemograms compatible with it could really have the disease. Difficulties in proving the infection and lack of knowledge about the duration of immunity conferred by the disease or vaccine confirmed this notion of non-acceptance of the diagnosis. These patients were labeled as presenting diseases of the differential diagnostic list of pertussis, such as, for example, infection by adenovirus.

Improvement in diagnostic methods, advances in studies on immunological responses to diseases and vaccines, the systematized studies of series of patients with compatible clinical diagnoses, using suitable scientific methods, the observation that these patients presented with a history of contact with individuals with prolonged coughing conditions, caused professionals to yield to the evidence that they were really facing an increase in the number of cases in infants, adolescents and adults.

This evidence and the possibility of using pertussis vaccine for groups beyond seven years of age, with the objective of preventing the transmission of $B$. pertussis to infants at risk of severe disease, justify the importance of this review for pediatric practice, in the light of scientific literature.

\section{Considerations about $B$. pertussis}

Knowledge about the molecular mechanisms in $B$. pertussis pathogenesis has increased over the last few years, which has provided important advances in vaccine research. ${ }^{8}$

B. pertussis is a small gram-negative aerobic coccobacillus, in whose gender there are another six species. The virulence factors of this bacterium have been elucidated by means of studies with other species of the gender, with which they share many toxins and adhesion molecules. The diversity of structural components, production of enzymes, toxins and other proteins, make this microorganism somewhat complex, and their mechanisms in pertussis pathogenesis is not yet completely understood. ${ }^{9}$

The virulence factors are typically divided into two main categories: adhesins and toxins. The adhesin group, which promotes bacteria adhesion to the epithelium, includes filamentous hemagglutinin, fimbriae, pertactin, resistance to bacterial destruction factor and tracheal colonization factor. It comprises the following group of toxins: pertussis toxin, adenylcyclase, dermonecrotic toxin and tracheal cytotoxin. ${ }^{8}$

Pertussis toxin induces the production of high antibody levels, and has therefore been considered a fundamental component in acellular vaccines. This toxin is responsible for the characteristic leukocytosis and lymphocytosis observed in pertussis cases. ${ }^{8,9}$

Filamentous hemagglutinin also promotes a strong antibody response, both systemic and mucosal. The stimulus in the host's immunological response is also determined by fimbriae and pertactin, an apparently important antigen for vaccines. 8,9

Bordetella, like other bacteria, is capable of regulating the expression of its virulence factors in response to environmental changes. ${ }^{9}$

\section{Natural immunological response and response to immunization}

Unlike other immuno-preventable diseases, such as diphtheria and tetanus, in which the antibody titers associated with protection have been determined, in the 
case of pertussis no serological immunity correlates have been established. 10

There may be an explanation for this situation in that protection against pertussis would appear to be multifactorial, involving humoral, cellular and mucosal immunity. Thus, studies that include the different types of immunity for long-term assessment of the protection induced by pertussis vaccines are considered to be necessary. ${ }^{10,11}$

Wendelboe et al. ${ }^{12}$ warned about various factors that may make it difficult to assess the persistence of pertussis vaccine induced immunity, as well as to limit the comparability among different studies, such as: the existence of various types of vaccines, alteration in vaccine compositions, use of non-uniform schemes, divergence in case definitions and presence of problems in the epidemiologic surveillance system.

\section{Natural immunologic response}

Various studies have been developed with the objective of investigating immunologic response behavior after developing infection by $B$. pertussis. In these studies it has been noted that the lowest immunity duration was around three to five years. At present the trend is to consider immunity duration of between 7 to 10 years and 20 years (Table 1). ${ }^{13-17}$ The differences in the results shown may be related to the different etiologic agent circulation levels, different epidemiologic surveillance systems, and different definitions of case. ${ }^{12}$

\section{Acellular vaccine induced immunologic response}

High efficacy levels have been obtained both with whole cell and acellular anti-pertussis vaccine. Protection duration following the basic vaccination scheme with one booster dose of whole cell vaccine is estimated to be between 6 and 12 years, the same period occurring after natural infection. Some studies have shown that the protection duration with the use of acellular vaccine is within the same time range. ${ }^{18}$
Maternal antibodies do not appear to influence the response to the vaccine against tetanus, diphtheria and acellular pertussis (TDaP) vaccines in infants, but do interfere in the response to the triple whole cell bacterial vaccine (DTPw). ${ }^{9}$

In the 1990's, an important study including various countries was conducted, with the objective of investigating acellular vaccine induced immunity against pertussis and its efficacy (Table 2).12,19-22

Forsyth et al. ${ }^{23}$ affirmed that the duration of acellular vaccine induced immunity is around five to six years. Schllekerez et al. ${ }^{24}$ mention that one year after vaccine application, protection against severe cases of pertussis is approximately $100 \%$, against cases of typical disease it is close to $90 \%$, and against moderate disease it is $70 \%$.

The majority of studies mentioned up to now used the presence of anti-pertussis antibodies (anti-toxoid, filamentous anti-toxin and anti-pertactin) to assess the immunologic response.

Edelman et al. ${ }^{11}$ investigated the long term immunity duration after a booster dose applied in adolescents. These authors observed that after three years, $82 \%$ to $100 \%$ presented with detectable antibody levels and $92 \%$ presented with cellular immunity.

The booster dose in adults also induced an important serological response initially, which diminished significantly after one year. 11,23

Halperin 25 reports that the reduction in antibody levels and cellular immunity after vaccine application is similar to that which occurs after the disease. Tan et al. ${ }^{26}$ agree with this statement, mentioning that natural immunity and that induced by the vaccine are lost in around five to eight years after the booster dose.

In the face of prevailing doubts about immunologic response, long-term follow-up of adolescents and adults who receive the triple acellular vaccine is of fundamental importance. Information about immunity duration is important for defining the time interval between subsequent doses. ${ }^{11}$

Table 1 - Selected articles about the duration of protection acquired by natural infection by $B$. pertussis

\begin{tabular}{lcccc}
\hline Authors & $\begin{array}{c}\text { Participants } \\
(\mathbf{n})\end{array}$ & $\begin{array}{c}\text { Data } \\
\text { sources }\end{array}$ & $\begin{array}{c}\text { Duration of } \\
\text { protection (years) }\end{array}$ & Country \\
\hline Laing \& Hay ${ }^{13}$ & 20,405 & Cohort & Lifelong & USA \\
Gordon \& Hood ${ }^{14}$ & Not applicable & Review & Lifelong & - \\
Von König W et al. ${ }^{15}$ & 369 & Home contacts & 20 & Germany \\
Miller \& Gay 16 & Not applicable & Review & 7 to 10 & UK \\
Versteegh et al. ${ }^{17}$ & 4 & Case reports & 3.5 to 12 & Holland
\end{tabular}

Source: adapted from Wendelboe et al. ${ }^{12}$ 
Table 2 - Selected articles about the duration of acellular vaccine induced protection against pertussis

\begin{tabular}{|c|c|c|c|c|}
\hline Author & $\begin{array}{l}\text { Participants } \\
\text { (n) }\end{array}$ & Data sources & $\begin{array}{c}\text { Duration of } \\
\text { protection (years) }\end{array}$ & Country \\
\hline Simondon et al. ${ }^{19}$ & 4,181 & Case-contact & $\begin{array}{c}\text { Whole cell > } \\
\text { acellular vaccines }\end{array}$ & Senegal \\
\hline Tindberg et al. ${ }^{20}$ & 207 & $\begin{array}{l}\text { Post-vaccination } \\
\text { follow-up }\end{array}$ & 5.5 & Sweden \\
\hline Salmaso et al. ${ }^{21}$ & 8,432 & Efficiency study & 6 & Italy \\
\hline Lugauer et al. ${ }^{22}$ & 10,271 & cohort & 6 & Germany \\
\hline
\end{tabular}

Source: adapted from Wendelboe et al. ${ }^{12}$

Furthermore, the recommendation to conduct research studies that focus on the immunity mechanisms mediated by $T$ cells and mucosal immunity is reiterated. ${ }^{12}$ The best period to apply booster doses to adolescents and adults is a matter of concern. ${ }^{9}$

\section{Considerations about pertussis epidemiology in the world and in Brazil}

The WHO estimates that 20 to 40 million pertussis cases occur annually all over the world, leading to around 200 to 400 thousand deaths. Lethality in developing countries may reach $15 \% .^{27}$

Even in countries with high vaccinal coverage, pertussis continues to be an important public health problem. Recent WHO data show that in 2003, around 17.6 million cases occurred, $90 \%$ of which were in developing countries, and that around 279,000 patients died. From these data, it is estimated that global vaccine cover could prevent around 38.3 million cases and 607,000 deaths. ${ }^{18}$

A dramatic reduction in the incidence of pertussis (>90\%) was observed in industrialized countries after large scale vaccination in the 1950s and 1960s. In 1974, the WHO Expanded Immunization Program incorporated the vaccine against diphtheria, tetanus and pertussis, the latter with whole cells. At the end of the 1980s, approximately $80 \%$ of children in the world received the vaccine. 18

B. pertussis continues to circulate, even in countries with high vaccine cover, affecting non-immunized children, adolescents and adults who have already lost the immunity conferred by previous vaccination or natural infection. The interval between outbreaks of pertussis epidemics has increased in these countries, peaks of incidence being observed every four years, with a prevalence of cases in higher age groups and in non-immunized or incompletely vaccinated infants. These findings have been observed in countries in Europe, Australia, Canada and the United States. ${ }^{18}$

Among the possible hypotheses to explain the apparent reappearance of the disease in the United States and in other countries where children are universally immunized are the following: 1 ) possible genetic changes in $B$. pertussis, making the vaccines less effective; 2) less potent vaccines; 3 ) progressive loss of vaccine induced immunity; 4) current better knowledge of bacteria and 5) availability of better diagnostic tests. ${ }^{28}$

The key to understanding pertussis is to recognize that the epidemiology of notified cases differs from the epidemiology of infection by $B$. pertussis. Specifically, notification peaks have occurred every three years, while the infection is endemic with regular transmission between adolescents and adults. ${ }^{28}$

As previously mentioned, the age groups most affected by pertussis over the last few years are infants, adolescents and adults. Of the 29,048 cases notified to the Centers for Disease Control and Prevention (CDC) in the USA between 1997 and 2000, 29\% occurred in infants under the age of one year, $29 \%$ in adolescents between 10 and 19 years of age and $20 \%$ in individuals over the age of 20 years. ${ }^{29}$

In the early 1980s, 40 thousand cases were notified annually in Brazil, and the coefficient of incidence for pertussis was higher than $30 / 100,000$ inhabitants. This figure dropped abruptly as from 1983, and has tended to decrease since then. In 1990, 15,329 cases were notified, resulting in a coefficient of incidence of $10.64 / 100,000$ inhabitants, and as from 1996, the annual number of cases has not exceeded 2,000 , thus maintaining a coefficient of incident of around 1/100,000 inhabitants. Since the institution of the Programa Nacional de Imunizações (Brazilian National Immunization Program) in 1973, when triple bacterial vaccine (DTP) began to be recommended for children under the age of seven, a decline in the incidence of pertussis has been observed, although the 
initial vaccinal coverage was not high. As from the 1990s, coverage increased, mainly after 1998, resulting in an important change in the epidemiological profile of this disease. In 2003, the Brazilian Ministry of Health was notified of 1,111 cases. 30

The source of $B$. pertussis infection has almost invariably been attributed to the children's family members, frequently parents or older siblings. ${ }^{31-33}$

As in other countries, in Brazil the positivity of the culture for $B$. pertussis or the polymerase chain reaction (PCR) has been shown in the family members of children with proven diagnoses. ${ }^{34}$

In a study conducted in Germany, the attack rate among unvaccinated children between six and 47 months of age was $69 \%$ ( 110 cases of pertussis among 160 contacts) and $31 \%$ in adults ( 76 cases among 264 contacts). The attack rate in women was significantly higher when the case index was a child, indicating closer proximity. 35

Of the nine pertussis cases in infants related by Smith $\&$ Vyas, ${ }^{1}$ all had a history of presence of family members with symptoms suggestive of pertussis, and in six of these cases, the family member was the mother.

In a study of 33 children with confirmed pertussis diagnosis, $69 \%$ had diagnosis confirmed in family members; in $42 \%$ the source was identified as the parents; and in $27 \%$ in the older siblings. ${ }^{4}$

\section{Considerations about the clinical characteristics and case definition of pertussis}

Characteristically, pertussis is manifested by coughing lasting several weeks, which starts mildly in the so-called catarrhal stage of the disease. In this stage, the predominant signs and symptoms are a runny nose and slight cough. In the paroxystic stage, it becomes established with accentuated coughing that progressively presents in fits, followed by an intense and characteristic inspirative noise called "whooping." Frequently the patient vomits after these attacks. The convalescent phase may last several weeks or even months, with progressive reduction in the frequency and intensity of the coughing episodes. If there are no complications, such as secondary bacterial infections, patients general do not present with fever. Commonly observed complications include pneumonia, otitis media, convulsions and encephalopathy. The clinical manifestation spectrum varies with the child's age, and is particularly more serious in infants, in whom apnea and convulsions may occur, with approximately $1 \%$ lethality. 9,27

Recent studies have shown that pertussis may present milder clinical manifestations with greater frequency than was previously thought. A study conducted in Germany with 1,860 cases of pertussis confirmed by nasopharynx culture, showed that $38 \%$ of the patients presented with coughing for only 28 or fewer days; in $18 \%$ of the cases coughing was not paroxystic; $21 \%$ did not present with the characteristic whooping; and in $47 \%$ of the patients there was no report of vomiting after coughing. ${ }^{36}$

When comparing the clinical manifestations with a duration of 21 or more days, observed in 180 patients infected by $B$. pertussis and parapertussis after the introduction of acellular pertussis vaccine, Liese et al. ${ }^{37}$ found that the characteristic clinical condition of pertussis was more frequent in patients with culture positive for $B$. pertussis. It was evidenced that $53 \%, 22 \%$ and $8 \%$ of the patients with $B$. pertussis presented with paroxystic coughing, whooping and post-cough vomiting, respectively, compared to $22 \%, 5 \%$ and $0 \%$, respectively, of those with culture positive for $B$. parapertussis. These same authors observed that the characteristic paroxystic coughing with a duration equal to or longer than 21 days in the 116 patients with confirmed diagnosis of $B$. pertussis infection, was evidenced in $83 \%$ of the patients who were not previously vaccinated against pertussis, compared with $41 \%$ among those who had received the vaccine.

The change in the clinical pattern of the disease in previously vaccinated individuals was shown by Tozzi et al. 38 in 788 confirmed pertussis cases. Cough duration among the non-vaccinated ranged from 52 to 61 days, while among those who were vaccinated it lasted 29 to 39 days. These authors argued that for pertussis case definition, these peculiarities must be taken into consideration.

Some authors warn about the possibility of not diagnosing pertussis in children hospitalized with serious unrecognized diseases. Crowcroft et al. ${ }^{2}$ reported confirmation of disease diagnosis in $20 \%$ of 142 children under the age of five months, admitted to the intensive care unit with life-threatening respiratory insufficiency, apnea and/or bradycardia. Forty per cent of these patients' parents were the source of infection and in $27 \%$, the older vaccinated siblings were the source.

Hope $^{39}$ mentions that pertussis in newborns is more frequent than has been diagnosed, and apparently the transfer of maternal pertussis antibodies does not appear to protect the conceptus. The serum antibodies against one or more $B$. pertussis components are important, but cellular and mucosal immunity also play a relevant role.

For the effect of notification, the WHO defines a suspected case of pertussis as being when an individual presents with coughing lasting 14 days or longer, coughing of any duration with paroxysm or coughing of any duration with whooping. The clinical definition of case is established when the physician determines the diagnosis or when an individual presents with coughing lasting for at least two weeks, in addition to at least one of the following findings: paroxysm, inspirative noise, and post-cough vomiting without justifiable cause. Laboratory confirmation is done 
by isolating $B$. pertussis in a proper culture medium, detecting the genomic sequence of the bacteria or paired positive serology. 40

The Brazilian Ministry of Health defines a case as suspected of pertussis when an individual, independently of age and vaccinal status, has presented with a dry cough for 14 days or longer, associated with one or more of the following symptoms: paroxystic cough (sudden, uncontrollable coughing, with fast short coughs, 5 to 10 in a single expiration); inspirative whooping; post-cough vomiting; or when an individual, independently of age and vaccinal status, has presented with a dry cough for 14 days or longer, with history of contact with a case of pertussis confirmed by clinical criteria. Suspected cases are considered confirmed by laboratory criteria when $B$. pertussis is isolated, or by epidemiological criteria when the suspected case has been in contact with a case confirmed by laboratory criteria, between the beginning of the catarrhal period through to three weeks after the beginning of the paroxystic period of the disease (transmittable period). 41

\section{Laboratory diagnosis}

It is important to have laboratory exams performed to confirm the disease caused by $B$. pertussis. This affirmation is backed by the difficulty of clinical diagnosis, which occurs relatively frequently in atypical manifestations of the disease. This mainly happens when the disease affects infants under the age of six months, adults and adolescents, as well as previously vaccinated individuals. 24,42 Furthermore, there are other microorganisms responsible for symptoms similar to those caused by $B$. pertussis, leading to a differential diagnosis. 10,43

The following will depend on elucidating the diagnosis: the patient's suitable treatment, guidance on prophylaxis for the contacts, real knowledge about incidence and lethality, among other epidemiologically relevant indicators.

Different laboratory techniques have been used for diagnosing pertussis. Up to 1996 , in the USA, culture was the recommended exam; from this year onwards, the PCR test was included. ${ }^{44}$ The National Health and Medical Research Council of Australia recommends carrying out culture or IgA anti $B$. pertussis research or antigen research in nasopharynx matter (immunofluorescence). France includes the Western blot test to investigate cases. 26

In Brazil, the Ministry of Health recommends $B$. pertussis isolation by means of culture of specimens collected from the nasopharynx with suitable technique. Etiologic diagnosis must always be made in outbreak situations.

The CDC in the United States recommends cultures and the PCR test to be done up to the third week after coughing begins or up to the fourth week after symptoms begin. The PCR test has the advantage of being more sensitive than culture, detects small quantities of the microorganism $(<10)$ which do not need to be stable. It can also detect different types of Bordetella. However, false-positive results may be a problem. ${ }^{26,44}$ When the suspected diagnosis is made between the third and fourth week after coughing begins, serology is the most indicated exam. 44

Antibody research is useful, mainly when suspicion is delayed and it is no longer possible to detect the microorganism. The most frequently used technique is ELISA (IgG antibody research by immunoenzymatic test). The following antibodies are counter components of $B$. pertussis: filamentous hemagglutinin, fimbriae and pertactin. 45

The above mentioned laboratory tests present some limitations. The immunofluorescence technique has lower sensitivity and specificity than culture. Culture in turn has the advantage of allowing antigenic variation and sensitivity to antibiotics to be characterized, but may undergo alteration by the very nature of the agent, with loss of viability while transporting it. 44,45

The PCR test has the advantage of being more sensitive than culture. It detects small quantities of the microorganism $(<10)$, which do not need to be stable. It can also detect different types of Bordetella. However, false-positive results may be a problem. ${ }^{25,42}$ Some authors argue in favor of standardizing laboratory techniques to assure the diagnostic quality and allow statistical data to be compared. 26,44

\section{Acellular pertussis vaccine for children over the age of seven years, adolescents and adults}

As previously mentioned, the incidence of pertussis among adolescents and adults has increased, and up until recently, there was no vaccine recommended for this age group. The triple bacterial vaccine available until then against diphtheria, tetanus and pertussis (DTPw), the pertussis being whole cell, was indicated only for children under the age of seven.

Over the last few years, several developed countries have been replacing this vaccine for children under the age of seven with an acellular pertussis component (TDaP). Finland and Norway use DTPw for basic immunization and TDaP as booster. Australia, Belgium, France, Germany, Israel, Italy, Japan, Sweden and the United States have abolished the use of DTPw. Among the countries represented in the group of international specialists that work on strategies to control pertussis (GPI), only Brazil and Argentina still use the DTPw vaccine. ${ }^{26}$ In 2005, the United Kingdom began to use TDaP in the basic immunization scheme.

In Brazil, the following presentations of the vaccine with acellular pertussis component are licensed: TDaP 
(internationally known as Pertacel ${ }^{\circledR}$ ); TDaP combined with parenteral vaccine against inactivated poliovirus and against Haemophilus influenzae type b - TDaP-IPV-Hib (internationally known as Poliacel ${ }^{\circledR}$ ) from the Sanofi Pasteur laboratory; TDaP-IPV-Hib (internationally known as Infanrix ${ }^{\circledR}$ ) and TDaP-IPV-Hib combined with hepatitis $B$ vaccine - TDaP-IPV-Hib-HB (internationally known as Infanrix-Hexa ${ }^{\circledR}$ ); Tdap-R (internationally known as Refortrix ${ }^{\circledR}$ or Boostrix ${ }^{\circledR}$ ) from the GlaxoSmithKline laboratory. Table 3 shows the various types of acellular vaccines currently available.

The two vaccines recommended as boosters for adolescents present similar immunologic response, and are highly immunogenic and safe. 25 Their formulas have approximately $1 / 3$ to $1 / 4$ of the concentration in relation to the pediatric formula. 10

The acellular pertussis vaccine combined with tetanic and diphtheria toxoids for adolescents and adults between the ages of 11 to 64 years, from the Sanofi Pasteur laboratory $\left(\right.$ Adacel $^{\circledR}$ ) was licensed in Canada in May 1999, based on safety, immunogenicity and effectiveness data. After over five years had elapsed, a publicly consolidated universal immunization program was implemented in all the provinces and territories of that country. ${ }^{46}$

In a study with 749 healthy adolescents and adults ranging between the ages of 12 to 54 years, the research participants were randomized into three groups: one group received double adult type vaccine against diphtheria and tetanus ( $\mathrm{dT}$ ), another group received the acellular vaccine formulation for adolescents and adults against pertussis (ap) and the other the triple vaccine formulation for adolescents and adults against tetanus, diphtheria e acellular pertussis (Tdap) from the Sanofi Pasteur laboratory (Adace ${ }^{\circledR}$ ). The adverse events were similar in the three groups, with less frequent pain at the injection site in the group that received only pa when compared with the group that received Tdap. There was no statistically significant difference between the acquisition of the antitoxin against tetanus and diphtheria between the groups that received dT or Tdap. The level of antibodies against $B$. pertussis antigens was high in all the groups, although the group that received only pa presented higher antibody levels against the pertussis toxin, fimbriae and agglutinins, and lower levels against pertactin, when compared with the group that received Tdap. 47

In September, 2003, the National Advisory Committee on Immunization (NACI) in Canada began to recommend that all pre-adolescents, adolescents and adults who had not received a booster dose of the acellular pertussis vaccine, must receive a single dose of the formulation for adolescents and adults. The Tdap type vaccine should

Table 3 - Different types of currently used triple bacterial vaccines against diphtheria, tetanus and acellular pertussis

\begin{tabular}{|c|c|c|c|c|c|c|}
\hline Indicated age & $<7$ years & $<7$ years & $<7$ years & $<7$ years & Adolescents & $\begin{array}{c}\text { Adolescents } \\
\text { and adults }\end{array}$ \\
\hline PT $(\mu g)$ & 20 & 10 & 25 & 25 & 8 & 2,5 \\
\hline $\mathrm{FHA}(\mu \mathrm{g})$ & 20 & 5 & 25 & 25 & 8 & 5 \\
\hline PRN $(\mu g)$ & 3 & 3 & 8 & 8 & 2.5 & 3 \\
\hline FIM $2+3(\mu g)$ & 5 & 5 & - & - & - & 5 \\
\hline \multicolumn{7}{|l|}{ Polio (D-Ag-U) } \\
\hline 1 & - & 40 & 40 & 40 & - & - \\
\hline 2 & - & 8 & 8 & 8 & - & - \\
\hline 3 & - & 32 & 32 & 32 & - & - \\
\hline Hep B (mg rec.) & - & - & - & 10 & - & - \\
\hline
\end{tabular}

Source: adapted from Pichichero et al. ${ }^{10}$

* In Brazil, the brand name is Refortrix ${ }^{\circledR}$.

$\mathrm{D}=$ diphtheria toxoid; FHA = filamentous hemagglutinin; FIM 2+3 = fimbriae 2 and $3 ;$ GSK = GlaxoSmithKline; Hep B = hepatitis B vaccine; $\mathrm{Hib}=$ Haemophilus influenzae type $b$ vaccine; $\mathrm{Lf}=$ limits of flocculation; Polio = poliovirus 1,2 and 3 vaccine; $P R N=$ pertactin; $\mathrm{PT}=$ pertussis toxin; $\mathrm{rec}=$ recombinant antigen; $\mathrm{T}=$ tetanic toxoid. 
replace the dT vaccine for the booster dose in the immunization program. 48

The GlaxoSmithKline Biological (GSK) and Sanofi Pasteur formulations of acellular pertussis vaccine combined with diphtheria and tetanus were approved for the booster dose against pertussis for adolescents, by the US Food and Drug Administration (FDA) in 2005, to be applied in a single dose between 10 and 18 years of age and from 11 to 64 years of age, respectively. ${ }^{49}$

In January, 2006, the Advisory Committee on Immunization Practices (ACIP) began to recommend the use of Tdap vaccine for adolescents between 11 and 12 years of age who had completed the childhood vaccination scheme against diphtheria, tetanus and pertussis, and for those who had not received the booster dose against tetanus and diphtheria. According to ACIP, adolescents between the ages of 13 and 18 years who were not vaccinated with dT or Tdap between the ages of 11 and 12 years, must also receive a single dose of Tdap vaccine, if their childhood vaccination scheme is complete. For subsequent boosters every 10 years, the ACIP continues to indicate $\mathrm{dT}$ vaccine. ${ }^{50}$ In addition to Canada, France, Germany and Australia changed the vaccination recommendations against pertussis, based on the increased number of cases (Table 4).

In Brazil only Refortrix ${ }^{\circledR}$ (Boostrix ${ }^{\circledR}$ ), the GSK vaccine brand name, is licensed and sold up to now, indicated for booster vaccination of adolescents and adults from 10 years of age onwards. The Sanofi Pasteur product, with the brand name Adacel ${ }^{\circledR}$ in other countries, had not been registered in Brazil up to January 2006.

The response of the GSK Tdap vaccine was assessed in 264 adolescents with regard to humoral immunity, and in
49 with regard to cellular immunity, 40 months after receiving the booster dose. The results were compared with a control group of adolescents that received only dT vaccine during the same period. Cellular response was maintained higher than before the booster dose in the first group. The antibody levels diminished over the course of three years after receiving the dose, but remained at higher levels than the initial level. The antibody response against pertussis antigens and the cellular response to filamentous hemagglutinin and pertactin were significantly higher in individuals that received Tdap, when compared with the control group, indicating that the effect could not be a consequence of possible contacts with $B$. pertussis in circulation. ${ }^{11}$

Purdy et al. ${ }^{51}$ assessed the cost-effectiveness of seven independent strategies for administering the booster pertussis vaccine, in the form of the combined vaccine against diphtheria, tetanus and acellular pertussis for adolescents and adults. The following strategies were assessed: a) vaccinate all adolescents between 10 and 19 years of age; b) adults 18 years of age or older and persons with chronic obstructive pulmonary disease; c) all adults 50 years of age or older; d) health area workers; e) universal vaccination of all persons ten years of age or older; f) persons living in the same house as children under the age of one year; g) all adults 20 years of age or older. The lowest cost strategy was to immunize adolescents between 10 and 19 years of age, which would prevent from 0.7 to 1.8 million pertussis cases in the United States at a saving of 0.6 to 1.6 billion dollars every decade. The authors argued that to apply the vaccine every 10 years would require more information as regards immunity, program costs, adhesion to vaccination and non-medical costs associated with pertussis.

Table 4 - Modification in the vaccination calendar against pertussis in some countries with increased incidence of the disease in adolescents and adults

\begin{tabular}{|c|c|c|c|}
\hline Country & Previous Calendar & Revised Calendar & Vaccines Used \\
\hline Canada & $\begin{array}{c}2-4-6 \text { months } \\
4-6 \text { years }\end{array}$ & $\begin{array}{c}2-4-6 \text { months } \\
4-6 \text { years } \\
14-16 \text { years }\end{array}$ & $\begin{array}{l}\text { TDaP-IPV-Hib } \\
\text { TDaP-IPV } \\
\text { Tdap }\end{array}$ \\
\hline France & $2-3-4-16-18$ months & $\begin{array}{c}2-3-4-16-18 \text { months } \\
11-13 \text { years }\end{array}$ & $\begin{array}{l}\text { DTPw-IPV-Hib } \\
\text { Tdap }\end{array}$ \\
\hline Germany & $2-3-4-11-18$ months & $\begin{array}{c}2-3-4-11-18 \text { months } \\
14-16 \text { years }\end{array}$ & $\begin{array}{c}\text { TDaP-IPV-Hib-HBV } \\
\text { Tdap }\end{array}$ \\
\hline Australia & $\begin{array}{c}2-4-6-18 \text { months } \\
4 \text { years }\end{array}$ & $\begin{array}{c}2-4-6 \text { months } \\
4 \text { years } \\
15-17 \text { years }\end{array}$ & $\begin{array}{c}\text { TDaP-HBV or TDaP } \\
\text { TDaP } \\
\text { Tdap }\end{array}$ \\
\hline
\end{tabular}

Source: adapted from Halperin $\mathrm{AS}^{46}$

$\mathrm{TDaP}$ = vaccine against diphtheria, tetanus and acellular pertussis; Tdap = formulation of the vaccine against diphtheria, tetanus and acellular pertussis for adolescents and adults; DTPW = vaccine against diphtheria, tetanus and whole cell pertussis; HBV = hepatitis $\mathrm{B}$ vaccine; Hib = Haemophilus influenzae type $\mathrm{b}$ vaccine; IPV = parenteral inactivated polio vaccine. 
Forsyth et al. 52 mentioned that booster vaccination strategies against pertussis are required. The expanded vaccination program must include additional doses in the existent schemes for pre-schoolchildren and adolescents, and booster doses for specific sub-groups of adults with greater risk for transmitting $B$. pertussis to infants, such as, for example, parents and others in contact with newborns, and health professionals. Universal adolescent vaccination must be implemented in countries where it is economically feasible.

The efficacy of an acellular pertussis vaccine for adolescents and adults was assessed in an extensive, multi-centric, randomized double-blind study with 2,781 individuals between the ages of 15 and 64 years, of whom 1,391 received acellular pertussis vaccine and 1,390 received hepatitis $A$ vaccine, as control. The individuals were monitored for 2.5 years for the occurrence of disease with coughing lasting longer than five days, tested by culture and PCR of nasopharyngeal aspiration, in addition to serum samples for antibody research against nine $B$. pertussis antigens in the acute and convalescent phases. The vaccine was shown to be safe and immunogenic. There were 2,672 episodes of prolonged coughing, whose incidence was no different between the two groups. Vaccine protection was $92 \%$ (95\%CI $32-99 \%)$. The incidence of pertussis among the non-immunized was $0.7 \%$ to $5.7 \%$. The authors concluded that the vaccine protects adolescents and adults against pertussis, reduces the incidence of the disease and its transmission to children. 53

The argument for replacing the double bacterial vaccine booster by acellular triple bacterial vaccine is increasingly consistent. The vaccinal scheme proposed for adolescents and adults is the use of a systematically applied booster dose. There is still no consensus about suitable guidance for individuals who do not know their vaccinal history, or who did not receive the triple bacterial vaccine in childhood. Producer laboratories recommend the application of this vaccine only as a booster dose for the age group over 10 years of age. For those who recently received a booster dose of the double bacterial vaccine, it is necessary to wait for at least 10 years for the application of tetanic and diphtheria toxoids. ${ }^{10}$

Adverse events with the booster dose of triple acellular bacterial vaccines are rare. The literature shows that the most frequently cited event is local edema mediated by IgE. Several authors have shown that the type and frequency of adverse events are practically the same for those who receive the double bacterial booster and for those who receive the triple acellular bacterial vaccine.

\section{Final considerations}

The availability of vaccine against diphtheria, tetanus and pertussis for adolescents and adults and its universal use is perhaps the only solution to the problem of the "reappearance" of pertussis. ${ }^{27}$ However, there are some aspects that require a great deal of further study, such as:

a) The question of multifactorial immunity; that is, what is the correspondence between the presence of humoral immunity and protection from the vaccine, and what is the role of cellular and mucosal immunity? With these doubts, it has not been possible to establish the duration of vaccine induced immunity and define the interval between boosters. Some authors affirm that immunity duration may vary in different regions, as it is influenced by the natural "booster" ( $B$. pertussis circulation). 12

b) The epidemiologic and economic impact. In view of the possibility of controlling pertussis, several studies on the impact of the vaccine have been conducted. Hay \& Ward ${ }^{42}$ and Caro et al. ${ }^{54}$ showed a favorable costbenefit ratio for the routine use of the vaccine in adolescents and adults. Pichichero et al. ${ }^{10}$ mentioned that the major impact of the disease on adults is not related to gravity or to lethality. In this group, the major problem is the loss of working days and reduction of productivity;

c) Reliability of statistical data. The unavailability of resources for laboratory investigation of cases, the difficulty of making clinical diagnoses of the disease, especially in adolescents and adults, and the undernotification are factors that make it difficult to assess the impact of the vaccine. ${ }^{25}$

Scientific research must elucidate these points in the short term and provide a better basis for immunization policies in different regions.

Perhaps the strategy of using a booster dose in adolescence and replacing the double vaccine against diphtheria and tetanus is a measure to be indicated immediately.

Another aspect that should perhaps be considered is the use of the vaccine for individuals who have prolonged contact, or will come into contact with newborns or infants who have not received the basic vaccination scheme against pertussis.

\section{References}

1. Smith $\mathrm{C}$, Vyas H. Early infantile pertussis: increasingly prevalent and potentially fatal. Eur J Pediatr. 2000;159:898-900.

2. Crowcroft NS, Booy R, Harrison T, Spicer L, Britto J, Mok Q, et al. Severe and unrecognised: pertussis in UK infants. Arch Dis Child. 2003;88:802-6.

3. Vitek $C R$, Pascual FB, Baughman AL, Murphy TV. Increase in deaths from pertussis among young infants in the United States in the 1990s. Pediatr Infect Dis J. 2003;22:628-34.

4. Mikelova LK, Halperin SA, Scheifele D, Smith B, Ford-Jones E, Vaudry W, et al. Predictors of death in infants hospitalized with pertussis: a case-control study of 16 pertussis deaths in Canada. J Pediatr. 2003;143:576-81. 
5. Torvaldsen S, McIntyre PB. Effect of the preschool pertussis booster on national notifications of disease in Australia. Pediatr Infect Dis J. 2003;22:956-9.

6. Edwards KM. Overview of pertussis: focus on epidemiology, sources of infection, and long term protection after infant vaccination. Pediatr Infect Dis J. 2005;24(6 Suppl):S104-8.

7. Baptista PN, Magalhães V, Rodrigues LC, Rocha MA, Pimentel AM. Source of infection in household transmission of cultureconfirmed pertussis in Brazil. Pediatr Infect Dis J. 2005;24: 1027-8.

8. Locht C. Molecular aspects of bordetella pertussis pathogenesis. Int Microbiol. 1999;2:137-44.

9. Heininger $U$. Recent progress in clinical and basic pertussis research. Eur J Pediatr. 2001;160:203-13.

10. Pichichero ME, Rennels MB, Edwards KM, Blatter MM, Marshal GS, Bologa M, et al. Combined tetanus, diphtheria, and 5component pertussis vaccine for use in adolescents and adults. JAMA. 2005;293:3003-11.

11. Edelman KJ, He Q, Makinen JP, Haanpera MS, Tran Minh NN, Schuerman L, et al. Pertussis-specific cell-mediated and humoral immunity in adolescents 3 years after booster immunization with acellular pertussis vaccine. Clin Infect Dis. 2004;39:179-85.

12. Wendelboe AM, Van Rie A, Salmaso S, Englund JA. Duration of immunity against pertussis after natural infection or vaccination. Pediatr Infect Dis J. 2005;24(5 Suppl):S58-61.

13. Laing JS, Hay M. Whooping-cough: its prevalence and mortality in Aberdeen. Public Health. 1902;14:584-98.

14. Gordon JE, Hood RI. Whooping cough and its epidemiological anomalies. Am J Med Sci. 1951;222:333-61.

15. Wirsing von König $\mathrm{CH}$, Postels-Multani S, Bock HL, Schmitt HJ. Pertussis in adults: frequency of transmission after household exposure. Lancet. 1995;346:1326-9.

16. Miller E, Gay NJ. Epidemiological determinants of pertussis. Dev Biol Stand. 1997;89:15-23.

17. Versteegh FG, Schellekens JF, Nagelkerke AF, Roord JJ. Laboratory-confirmed reinfections with Bordetella pertussis. Acta Paediatr. 2002;91:95-7.

18. World Health Organization. Pertussis vaccines - WHO position paper. Wkly Epidemiol Rec. 2005;80:31-9.

19. Simondon F, Preziosi MP, Yam A, Kane CT, Chabirand L, Iteman $\mathrm{I}$, et al. Randomized double-blind trial comparing a twocomponent acellular to a whole-cell pertussis vaccine in Senegal. Vaccine. 1997; 15:1606-12.

20. Tindberg Y, Blennow M, Granstrom M. A ten year follow-up after immunization with a two component acellular pertussis vaccine. Pediatr Infect Dis J. 1999;18:361-5.

21. Salmaso $S$, Mastrantonio $P$, Tozzi AE, Stefanelli $P$, Anemona $A$, Ciofi degli Atti ML, et al. Sustained efficacy during the first 6 years of life of 3-component acellular pertussis vaccines administered in infancy: the Italian experience. Pediatrics. 2001;108: E81.

22. Lugauer $S$, Heininger $U$, Cherry JD, Stehr K. Long-term clinical effectiveness of an acellular pertussis component vaccine and a whole cell pertussis component vaccine. Eur J Pediatr. 2002;161:142-6.

23. Forsyth $\mathrm{K}$, Tan $\mathrm{T}$, von König $\mathrm{CH}$, Caro JJ, Plotkin S. Potential strategies to reduce the burden of pertussis. Pediatr Infect Dis J. 2005;24(5 Suppl):S69-74.

24. Schellekens J, Von König CH, Gardner P. Pertussis sources of infection and routes of transmission in the vaccination era. Pediatr Infect Dis J. 2005;24(5 Suppl):S19-24.

25. Halperin SA. Pertussis - a disease and vaccine for all ages. N Engl J Med. 2005;353:1615-7.

26. Tan T, Trindade E, Skowronski D. Epidemiology of pertussis. Pediatr Infect Dis J. 2005;24(5 Suppl):S10-8.

27. World Health Organization. Control of diphtheria, pertussis, tetanus, Haemophilus influenzae type $b$, and hepatitis B: field guide. Washington: WHO; 2005.

28. Cherry JD. The science and fiction of the "resurgence" of pertussis. Pediatrics. 2003;112:405-6.

29. Centers for Disease Control and Prevention (CDC). Pertussis United States, 1997-2000. MMWR Morb Mortal Wkly Rep. 2002;51:73-6.

30. Brasil, Ministério da Saúde, Secretaria de Vigilância em Saúde. Situação das doenças transmissíveis no Brasil. http:// portal.saude.gov.br/portal/svs/area.cfm?id_area=451. Access: $10 / 08 / 2004$.

31. Baron S, Njamkepo E, Grimprel E, Begue P, Desenclos JC, Drucker J, et al. Epidemiology of pertussis in French hospitals in 1993 and 1994: thirty years after a routine use vaccination. Pediatr Infect Dis J. 1998;17:412-8.
32. Halperin SA, Wang EE, Law B, Mills E, Morris R, Dery $P$, et al. Epidemiological features of pertussis in hospitalized patients in Canada, 1991-1997: report of the Immunization Monitoring Program - Active (IMPACT). Clin Infect Dis. 1999;28:1238-43.

33. Elliott E, McIntyre P, Ridley G, Morris A, Massie J, McEniery J, et al. National study of infants hospitalized with pertussis in the acellular vaccine era. Pediatr Infect Dis J. 2004;23:246-52.

34. Carvalho AP. Mesa redonda: vigilância epidemiológica. Coqueluche. In: XIV Congresso Brasileiro de Infectologia Pediátrica; 2005 abr 27-30; Foz do Iguaçu, Brasil.

35. Wirsing von König $\mathrm{CH}$, Postels-Multani S, Bogaerts $\mathrm{H}$, Bock $\mathrm{HL}$, Laukamp S, Kiederle $S$, et al. Factors influencing the spread of pertussis in households. Eur J Pediatr. 1998;157:391-4

36. Heininger $U$, Klich $K$, Stehr $K$, Cherry JD. Clinical findings in Bordetella pertussis infections: results of a prospective multicenter surveillance study. Pediatrics. 1997;100:E10.

37. Liese JG, Renner C, Stojanov S, Belohradsky BH; Munich Vaccine Study Group. Clinical and epidemiological picture of B pertussis and $B$ parapertussis infections after introduction of acellular pertussis vaccines. Arch Dis Child. 2003;88:684-7.

38. Tozzi AE, Rava L, Ciofi degli Atti ML, Salmaso S; Progetto Pertosse Working Group. Clinical presentation of pertussis in unvaccinated and vaccinated children in the first six years of life. Pediatrics. 2003;112:1069-75.

39. Hoppe JE. Neonatal pertussis. Pediatr Infect Dis J. 2000;19:244-7.

40. World Health Organization. Generic protocol for estimating the burden of pertussis in young children. Geneva: WHO; 2005.

41. Brasil, Ministério da Saúde do Brasil, Secretaria de Vigilância em Saúde, Departamento de Vigilância Epidemiológica. Doenças infecciosas e parasitárias - guia de bolso. 5a ed. Brasília: Ministério da Saúde; 2005. p. 81-4.

42. Hay JW, Ward JI. Economic considerations for pertussis booster vaccination in adolescents. Pediatr Infect Dis J. 2005;24(6 Suppl):S127-33.

43. Juretzko $P$, von Kries $\mathrm{R}$, Hermann $M$, Wirsing von König $\mathrm{CH}$, Weil J, Giani G. Effectiveness of acellular pertussis vaccine assessed by hospital-based active surveillance in Germany. Clin Infect Dis. 2002;35:162-7.

44. Hewlett EL, Edwards KM. Clinical practice. Pertussis - not just for kids. N Engl J Med. 2005;352:1215-22.

45. Davis JP. Clinical and economic effects of pertussis outbreaks. Pediatr Infect Dis J. 2005;24(6 Suppl):S109-16.

46. Halperin SA. Canadian experience with implementation of an acellular pertussis vaccine booster-dose program in adolescents: implications for the United States. Pediatr Infect Dis J. 2005;24(6 Suppl):S141-6.

47. Halperin SA, Smith B, Russell M, Hasselback P, Guasparini R, Skowronski $D$, et al. An adult formulation of a five-component acellular pertussis vaccine combined with diphtheria and tetanus toxoids is safe and immunogenic in adolescents and adults. Vaccine. 2000;18:1312-9.

48. National Advisory Committee on Immunization (NACI). Prevention of pertussis in adolescents and adults. Can Commun Dis Rep. 2003;29:1-9.

49. Cherry JD. Pertussis vaccines for adolescents and adults. Pediatrics. 2005;116:755-6.

50. United States of America, The Advisory Committee on Immunization Practices. Recommended childhood and adolescent immunization schedule - United States, 2006. MMWR. 2006;54:Q1-4.

51. Purdy KW, Hay JW, Botteman MF, Ward JI. Evaluation of strategies for use of acellular pertussis vaccine in adolescents and adults: a cost-benefit analysis. Clin Infect Dis. 2004;39:20-8.

52. Forsyth KD, Campins-Marti M, Caro J, Cherry JD, Greenberg D, Guiso N, et al. New pertussis vaccination strategies beyond infancy: recommendations by the global pertussis initiative. Clin Infect Dis. 2004;39:1802-9.

53. Ward JI, Cherry JD, Chang SJ, Partridge S, Lee H, Treanor J, et al. Efficacy of an acellular pertussis vaccine among adolescents and adults. N Engl J Med. 2005;353:1555-63.

54. Caro JJ, Getsios D, El-Hadi W, Payne K, O’Brien JA. Pertussis immunization of adolescents in the United States: an economic evaluation. Pediatr Infect Dis J. 2005;24(5 Suppl):S75-82.

Correspondence:

Aroldo P. de Carvalho

Rua Almirante Lamego, 1374/902

CEP 88015-600 - Florianópolis, SC - Brazil

Tel.: +55 (48) 3025.5051, +55 (48) 3251.9000,

+55 (48) 9983.0155

E-mail: aroldo@ccs.ufsc.br 